KRZYSZTOF HOLAK*, PIOTR KOHUT*, ANDRZEJ MŁYNIEC*, MARTYNA EKIERT*, KRZYSZTOF TOMASZEWSKI**, TADEUSZ UHL*

\title{
THE USE OF DIGITAL IMAGE CORRELATION IN THE STUDY OF ACHILLES TENDON STRAIN FIELD
}

\begin{abstract}
This paper presents an application of a vision-based measurement method in the experimental mechanics of biological materials. The displacement and strain fields of a human Achilles tendon specimen under a tensile test were computed using the digital image correlation method. Different software applications, both commercial and open source, were compared. The performance of algorithms was tested based on a referential measurement carried out by commercial software with the affine model of deformation implemented. The root mean square error of the difference between strain obtained using the reference measurement and each of the analyzed programs was computed. Additionally, an example of a full-field computation of displacement and strain field was presented.
\end{abstract}

Keywords: vision systems, digital image correlation, biomechanical measurements, human Achilles tendon

\section{ZASTOSOWANIE CYFROWEJ KORELACJI OBRAZÓW W BADANIACH POLA ODKSZTAECEŃ ŚCIĘGNA ACHILLESA}

Artykut przedstawia zastosowanie pomiarów wizyjnych $w$ mechanice eksperymentalnej badającej wtaściwości materiałów biologicznych. Pole przemieszczeń i odkształceń ludzkiego ścięgna Achillesa uzyskane podczas statycznej próby rozciagania zostało wyznaczone za pomoca algorytmu cyfrowej korelacji obrazów. Porównano kilka wybranych programów komputerowych, zarówno komercyjnych, jak i darmowych, realizujacych pomiar za pomoca metody korelacji. Skuteczność algorytmów była testowana na podstawie wyników referencyjnych, otrzymanych z komercyjnego programu, w którym została zaimplementowana korelacja oparta na deformowalnym modelu afinicznym. Wyznaczono błędy średniokwadratowe różnicy pomiędzy danymi referencyjnymi a danymi otrzymanymi z każdego z testowanych programów. Dodatkowo pokazano przykład uzyskanego pola przemieszczeń $i$ odkształceń na całej powierzchni testowanej próbki.

Stowa kluczowe: systemy wizyjne, cyfrowa korelacja obrazów, pomiary biomechaniczne, ludzkie ścięgno Achillesa

\section{INTRODUCTION}

The examination of the mechanical properties of all kinds of biological materials has become very important over the past several years. The investigation of tissue behavior under tension, compression, and other kinds of static and dynamic loads is necessary in many branches of material science, biomechanics, biomedical engineering, and areas of medicine and medical technology (like surgery, dentistry, and prosthetics). Scientists examine the mechanical properties of materials in order to understand the process of growth in human and animal organs and its behavior under the influence of various factors. The material parameters of skin, muscles, tendons, internal organs, and bones are obtained in ex vivo and in vivo experiments to provide more accurate data for the modeling of tissue using numerical finite elements as well as multi-scale methods. New materials developed for prosthetics and dentistry are investigated for better biocompatibility with the human organism and a closer similarity to natural tissue and organs. Control systems of robots used in surgical operations are designed for robot-tool interactions with soft and flexible biological materials.
The challenge for the investigators is the development of measurement techniques that can cope with specimens that are soft and shapeless under gravity, with a surface that must be wet during the time of examination. One of the most-important quantities that must be measured in laboratory experiments is the displacement or strain field of a sample under a given load condition. In the case of tensile or compressive tests under a static load, contact measurement devices are still used. For example, the LVDT (Linear Variable Differential Transformer) displacement sensor was applied for the mechanical characterization of brain tissue in tension (Rashid et al. 2014). In a fatigue test of a carbon fiber/epoxy plate, a contact extensometer was used to record strains (Bagheri et al. 2015). These methods of measurement are very simple and inexpensive; however, they have many drawbacks. They need time-consuming preparation and are hard to mount on a sample that is very soft (as in the case of most biological specimens). Moreover, these devices influence the material characteristics of examined materials and act as an additional load in both static and dynamic cases. Therefore, non-contact measurement techniques have become more important and popular. Among these methods,

\footnotetext{
* AGH University of Science and Technology, Faculty of Mechanical Engineering and Robotics, Department of Robotics and Mechatronics, Krakow, Poland; e-mail: holak@agh.edu.pl

** Jagiellonian University Medical College, Department of Anatomy, Krakow, Poland
} 
optical- and vision-based systems are frequently used. For example, the paper by Koh et al. (2014) presents a compressive test of saturated calcium sulphate dihydrate cements (a prosthetic material). The compression of a test sample was measured by two methods: by measuring the relative displacement of the top and bottom plates, and by using a video-extensometer. The image-processing algorithms were applied to detect and track two black horizontal lines marked on the sample. The elongation of the sample was computed as the difference between the displacements of the two markers. In another example, passive skeletal muscle response to impact loading was experimentally investigated in order to obtain data for inverse modeling (Takaza et al. 2013). Deformation of a porcine muscle specimen was examined by image-processing methods. Each sample was marked with nine dots on a sample surface prior to testing. The displacement of the dots was computed by a tracker implemented in the MATLAB programming environment. The strain field was estimated based on the measured displacements. Image processing is used to provide the geometry of a specimen for numerical modeling. Image-based 3D reconstruction software iModeller 3D professional was applied to construct a solid model of each specimen of a rabbit's vocal cords (Latifi et al. 2014). The samples were mounted on a rotating table in their initial state. A set of 18 images was captured for each specimen at different angles of rotation. A 3D surface model was constructed and stored in the STL (Stereolitography) format. The solid models were built using SolidWorks Software. The created objects were then imported to FEM (Finite Element Method) software. Nowadays, there are developed methods of in vivo tissue mechanical property characterization. Achilles tendon (AT) morphometry is carried out by means of ultrasound techniques (Obst et al. 2016). The geometry of AT and its changes are obtained based on ultrasound images acquired during an experiment. Another applied method (Arampatzis et al. 2010) is magnetic resonance imaging (MRI). The mechanical properties of the tendon are analyzed with the help of isokinetic dynanometers such as the Biodex System device (Bayliss et al. 2016). Another field of research that is frequently used in the laboratory is shear wave elastography imaging (Helfenstein-Didier et al. 2016). This method can be applied for the experimental evaluation of an AT shear modulus.

The most important technique for strain field computation used in experimental mechanics is the Digital Image Correlation (DIC) method. The method was initially developed for non-contact material testing but quickly found applications in all branches of science and technology. There are numerous applications of DIC in medicine and biology. A sample is prepared before each examination by spraying a random texture on its surface. Then, the deformation of the specimen is recorded by one (in the case of 2D DIC) or two digital cameras (3D DIC). The displacements of the measurement points are computed based on two images of the specimen: the reference one, and the images showing the sample under deformation. The strain field is obtained based on the displacement field. The DIC method became popular because of its simplicity, high accuracy, and ability to compute full-field strain data with the density of measurement points restricted only by the resolution of the image sensor used in the camera system. One of the applications of DIC in experimental mechanics of biological tissue is planar biaxial testing on fiber-reinforced skin grafts (Sahoo et al. 2014). The lab setup was equipped with a load cell and synchronized video system for strain analysis, which consists of a Prosilica GigE CCD camera and StreamPix videometric tracking system. The graft surface was sprayed with black paint to create a speckled pattern. The strain field was analyzed using the DIC technique and Vic2D software. Local Lagrangian strains were determined in the post-processing step. Cyganik et al. (2014) reported a bone-specimen testing in a uniaxial compression test on an MTS machine. A Dantec Dynamics Model Q-400 DIC two-camera system was used to measure 3D displacement and strain fields. The specimen was painted with white acrylic paint to create a random speckled pattern. Digital Volume Correlation is a method that measures the internal 3D displacement field of tested materials. Gillard et al. (2014) applied the method to examine the compressive properties of trabecular bone. An internal structure of cancellous bone cut out of a porcine femur was analyzed using microfocus X-ray computer tomography. The obtained projections were used to reconstruct a $3 \mathrm{D}$ volumetric model of a specimen. DVC computation was performed on the volumes using DaVis LaVision software. 3D strain fields were computed in MATLAB software based on the obtained displacement fields.

This paper shows the application of an image-based measurement method in the computation of strain of biological material subjected to tensile uniaxial loading. The examined tissue was a human Achilles tendon. The experiment was carried out on an Instron 8872 testing machine. The image sequence of sample deformation was captured by a Phantom v9.1 high-speed digital camera. The strain field was computed by means of the DIC method. Four different software tools were used, and 
the results were compared with MotionProX (which employs a deformable model of displacement). The RMS error of the computed strains is presented. The full fields of displacement and strain were computed using NCORR software.

\section{DIGITAL IMAGE CORRELATION - THEORETICAL BASICS}

Digital image correlation (DIC) is a passive vision-based technique introduced to experimental mechanics in the last decade of the 20th century. The method requires a single camera (in the case of 2D DIC) or calibrated stereo-vision system (3D DIC) and a source of light. The specimen has to be prepared before examination by spraying a random speckle pattern on its surface. In the case of samples having a natural random speckle pattern, this step may be omitted. During the experiment, a series of images of a specimen deforming under applied load is acquired. The first image is used to set up a DIC algorithm. A grid of measurement points is constructed, and a size of the correlation patch is chosen. The displacement field is computed based on pairs of images: the reference one and that which is acquired after the specimen's deformation. For each of the image pairs and image patches, a chosen deformation model is fit into the data. Its parameters are found by optimizing similarity criteria between the two image patches. As a result, a full field of displacement is obtained. The local strain in each measurement point can be calculated based on the displacement data. In order to measure displacement of a point, a square image patch with a center at the point and odd number of rows and columns is constructed. A pixel grid under the patch is taken as a reference pattern, and it is tracked by an algorithm over consecutive frames as the specimen deforms. For each frame, the deformation model's parameters are calculated based on the given similarity criteria. There are many deformation models reported in the literature, among which two are the most-commonly used: translational and affine. The most-general motion model can be described by an equation:

$$
\begin{aligned}
& x_{i}^{\prime}=x_{i}+\xi\left(x_{i}, y_{i}\right) \\
& y_{i}^{\prime}=y_{i}+\eta\left(x_{i}, y_{i}\right)
\end{aligned}
$$

where $\left(x_{i}, y_{i}\right)$ are coordinates of the center of the image patch in the reference frame, $\left(x_{i}^{\prime}, y_{i}^{\prime}\right)$ are the coordinates of the corresponding point in consecutive frames of a sequence, and functions $\xi$ and $\eta$ depend on the chosen deformation model. For the simplest translational model case, functions $\xi$ and $\eta$ can be replaced by:

$$
\begin{aligned}
& \xi\left(x_{i}, y_{i}\right)=u \\
& \eta\left(x_{i}, y_{i}\right)=v
\end{aligned}
$$

translational displacements of a center of the image patch. The model has two parameters and is suitable for the case of the very-small local deformation of a specimen. The affine model can be described by equation:

$$
\begin{aligned}
& \xi\left(x_{i}, y_{i}\right)=u+\frac{\partial u}{\partial x} \Delta x+\frac{\partial u}{\partial y} \Delta y \\
& \eta\left(x_{i}, y_{i}\right)=v+\frac{\partial v}{\partial x} \Delta x+\frac{\partial v}{\partial y} \Delta y
\end{aligned}
$$

The model has six parameters. It corresponds to the deformable correlation algorithm. An image patch deformed by the use of two models of deformation is presented in Figure 1. The position of an image patch center on each frame of a sequence is computed based on the maximum value of similarity criteria. The most-important criterion is zero-normalized cross correlation coefficient $\left(\mathrm{C}_{\mathrm{ZNCC}}\right)$ given by equation:

$$
\mathrm{C}_{\mathrm{ZNCC}}=\sum_{i=-M}^{M} \sum_{j=-M}^{M}\left\{\frac{\left[f\left(x_{i}, y_{i}\right)-f_{m}\right]\left[g\left(x_{i}^{\prime}, y_{i}^{\prime}\right)-g_{m}\right]}{\Delta f \Delta g}\right\}
$$

where:

$$
\begin{aligned}
& f_{m}=\frac{1}{(2 M+1)^{2}} \sum_{i=-M}^{M} \sum_{j=-M}^{M} f\left(x_{i}, y_{i}\right) \\
& g_{m}=\frac{1}{(2 M+1)^{2}} \sum_{i=-M}^{M} \sum_{j=-M}^{M} g\left(x_{i}^{\prime}, y_{i}^{\prime}\right) \\
& \Delta f=\sqrt{\sum_{i=-M}^{M} \sum_{j=-M}^{M}\left[f\left(x_{i}, y_{i}\right)-f_{m}\right]^{2}} \\
& \Delta g=\sqrt{\sum_{i=-M}^{M} \sum_{j=-M}^{M}\left[g\left(x_{i}^{\prime}, y_{i}^{\prime}\right)-g_{m}\right]^{2}}
\end{aligned}
$$

$f$ and $g$ are image patch intensity functions for the reference and analyzed images, and $M$ is the size of the image patch (number of pixels in the $x$ and $y$ directions). The $\mathrm{C}_{\mathrm{ZNCC}}$ coefficient is maximized over six parameters of the deformation model using the Gauss-Newton optimization technique. 


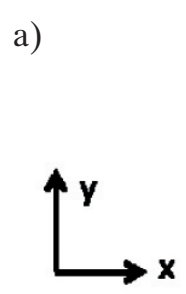

D

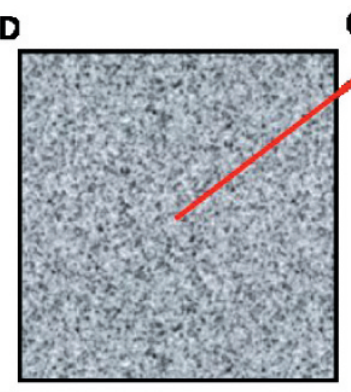

A

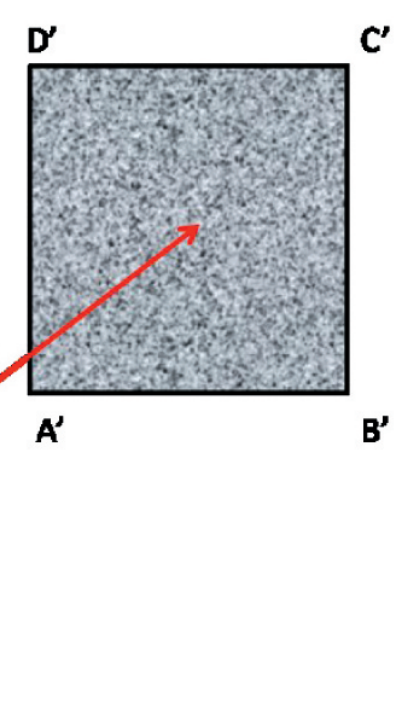

b)

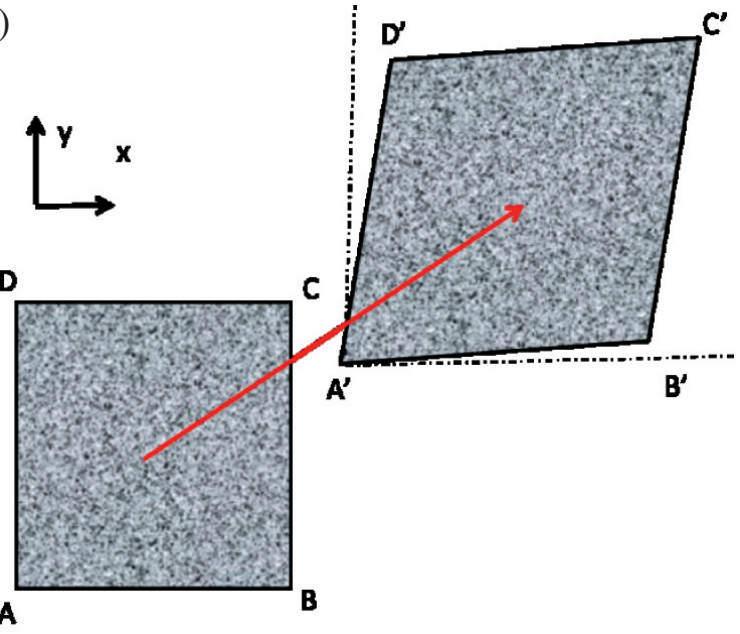

Fig. 1. Two models of deformation used in DIC software:

a) displacement model; b) affine deformation model

After performing the computations for all measurement points in an image grid, a full-field displacement field for a specimen is obtained. In the last step, $\varepsilon_{x x}, \varepsilon_{y y}$ and $\varepsilon_{x y}$ strain components are calculated using Green-Lagrange formulae:

$$
\begin{aligned}
& \varepsilon_{x x}=\frac{1}{2}\left(2 \frac{\partial u}{\partial x}+\left(\frac{\partial u}{\partial x}\right)^{2}+\left(\frac{\partial v}{\partial x}\right)^{2}\right) \\
& \varepsilon_{x y}=\frac{1}{2}\left(\frac{\partial u}{\partial y}+\frac{\partial v}{\partial x}+\frac{\partial u}{\partial x} \frac{\partial u}{\partial y}+\frac{\partial v}{\partial x} \frac{\partial v}{\partial y}\right) \\
& \varepsilon_{y y}=\frac{1}{2}\left(2 \frac{\partial v}{\partial y}+\left(\frac{\partial u}{\partial y}\right)^{2}+\left(\frac{\partial v}{\partial y}\right)^{2}\right)
\end{aligned}
$$

The 2D DIC algorithm provides full-field displacement and strain passive vision-based measurement. The method can be easily applied to the measurement of strain data in experimental mechanics and the mechanical testing of soft specimens of a biological origin.

\section{LABORATORY EXAMINATION OF ACHILLES TENDONS}

In order to carry out tests of the DIC-based vision algorithms, the tensile test of human tendon tissue was performed. The human Achilles tendon (AT) is one source of material used in reconstructive orthopedics to repair, for example, knee ligaments such as the cruciate anterior and posterior ligaments. Four different software tools were used to analyze the data obtained in the experiment. In the following sections of the article, the tools will be referred as DIC_1, DIC_2, DIC_3, and DIC_4.
Regarding the algorithm called DIC_1, the normalized cross-correlation coefficient given by equation (4) was implemented in the MATLAB programming environment for computation of the displacement field. The correlation coefficient computes the position of the pixel on the discrete pixel grid of the image. When the sub-pixel method is introduced, measurement accuracy can be enhanced by up to 0.01-0.1 parts per pixel (Sutton et al. 1986, 1991, Ma 2003). The fitting was computed by means of calculating the parabola coefficients and its maximum value.

The DIC_2 method represents a gradient-based method for displacement computation with sub-pixel accuracy. In this algorithm, a normalized cross correlation is computed in the first stage by employing MATLAB function normxcorr2. Then, the sub-pixel registration gradient based-method is applied to improve accuracy. This method was originally developed by Davis and Freeman for use in video compression and is based on first-order spatio-temporal gradients (Pan et al. 2006). This method starts with the assumption that image displacement is pure translation. This assumption holds true even for images where more-complex deformations are present if the subsets of pixels used for correlation and their displacements are small enough.

DIC_3 denotes the digital image correlation algorithm implemented in commercial MotionProX software. Displacements of the analyzed objects (patches) were estimated by applying a tracking algorithm. The deformable translation model was employed; therefore, the result obtained using this software was taken as a reference strain. 
In the case of DIC_4, the Tema software correlation tracker was chosen. The draw-back of this method is its sensitivity to rotation. The uncertainty of the correlation tracker amounted to 0.5 pixels. Tema allows different sizes and shapes of the template to set; for example, circle-, square-, and cross-shaped templates can be used. There is also the possibility to change the area of the search window, adjust the "update factor", or pre-process the analyzed images using the Sobel filter. The full-field computation of the strain field was carried out as the next step of the investigation. The NCORR software implemented in the MATLAB programming environment (which performs the 2D DIC method for a chosen image patch) was used. The software provides displacements in the $x$ and $y$ axes as well as three planar strain tensor components $\left(\varepsilon_{x x}, \varepsilon_{y y}\right.$, and $\left.\varepsilon_{x y}\right)$

\section{EXPERIMENTAL INVESTIGATION}

The experimental stand (Fig. 2) was composed of the following items: an Instron 8872 material-testing machine, high-speed camera Phantom v9.1 equipped with a Carl Zeiss $f=50 \mathrm{~mm}$ lens, and diode-based lighting systems (Visual Instrumentation Corp.). The optical axis of the camera was positioned perpendicularly with respect to the specimen surface. The camera settings were chosen as follows:

Phantom v.91.1 Camera:

lens: Carl Zeiss; focal length $50 \mathrm{~mm}$; F/8

Frame rate: $200 \mathrm{fps}$

Image resolution: $1344 \times 720$

Exposure: $0.8 \mathrm{~ms}$

Instron:

Speed: $1 \mathrm{~mm} / \mathrm{sec}$

Displacement: $30 \mathrm{~mm}$

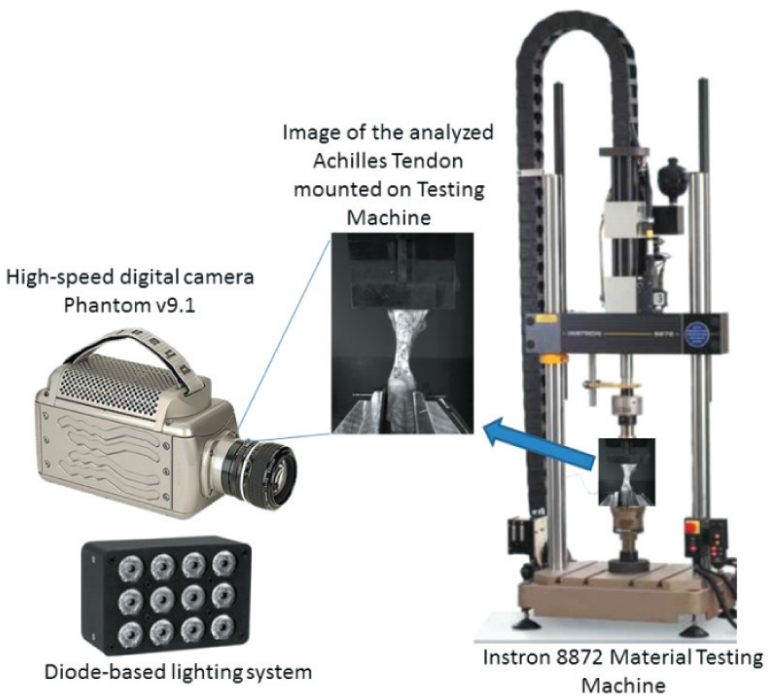

Fig. 2. Scheme of the experimental rig
A tensile test was performed on a prepared sample. Each specimen was composed of the Achilles tendon (AT) together with the calcaneus and a $5-\mathrm{cm}$ distal portion of the gastrocnemius. The specimen was placed in custom-made clamps and mounted in the Instron 8872 (where the tensile testing was carried out). To apply the digital image correlation method, the speckle pattern was placed on a specimen using black markers with various tip sizes. Four digital image correlation techniques were employed. As a result, the displacements of selected points were attained. The average strain at two chosen points of the specimen were computed based on the obtained displacements. The root-mean-square (RMS) error of strain was computed. As a reference measurement, DIC_3 MotionProX was used.

Before the experiment was carried out, measurement points were marked on a sample of the Achilles tendon (Fig. 3). These points were tracked in an image sequence using all of the chosen DIC software. For tensile strain computation, the change of distances between two pairs of points (according to Figure 3, points 2 and 3, and points 3 and 5) was calculated. The strain was taken as the change of distance divided by the reference distance between two points taken from the first image of the sequence. Additionally, the computation of the 2D displacements and strain fields for the entire sample's surface were carried out using NCORR software (Fig. 4).

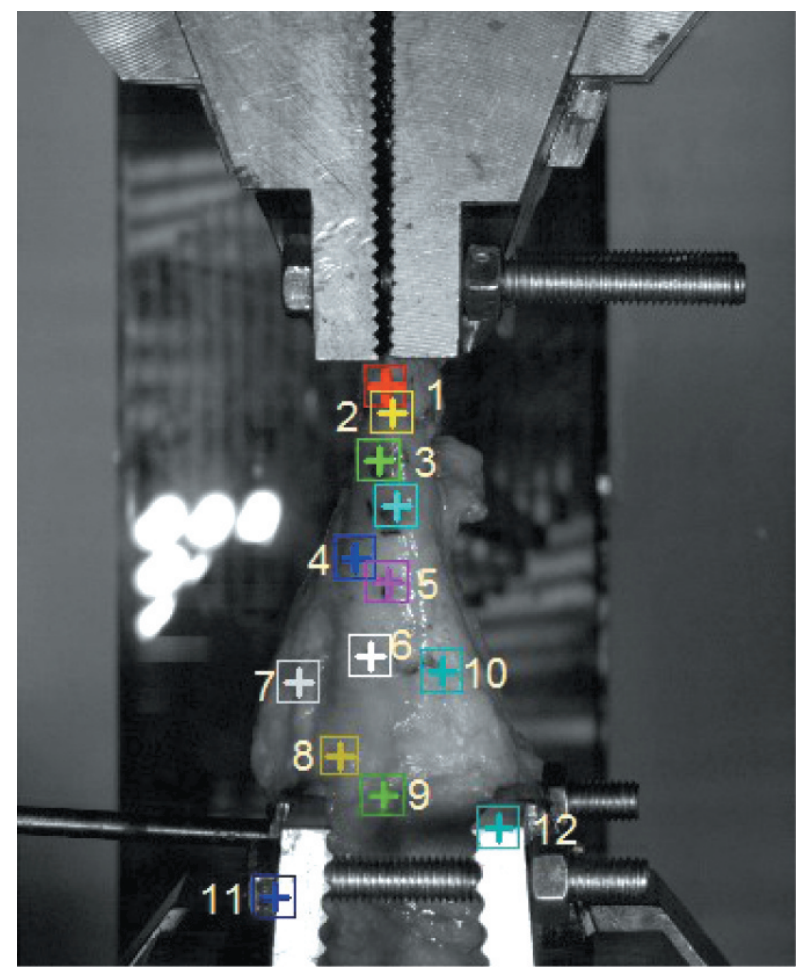

Fig. 3. Achilles tendon tested in the experiment. Points tracked by DIC method during tensile test are marked by crosses 
a)

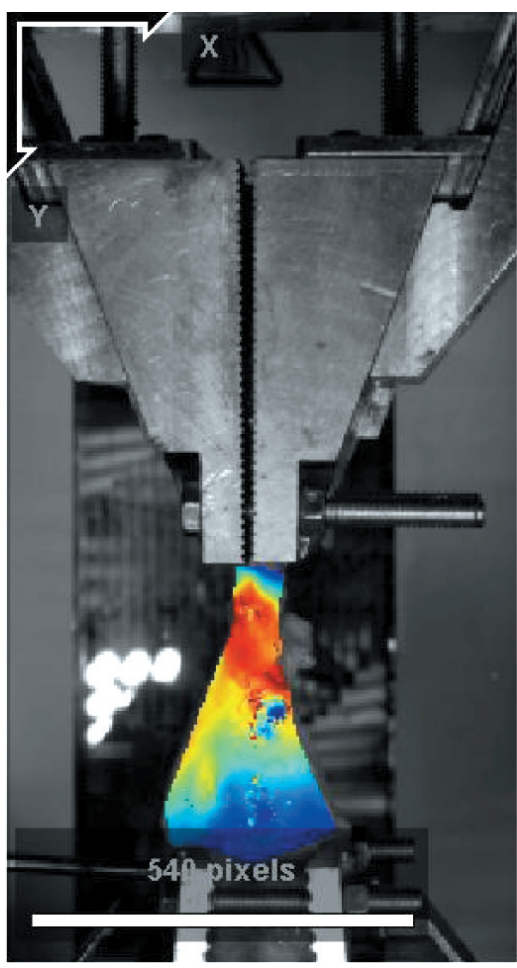

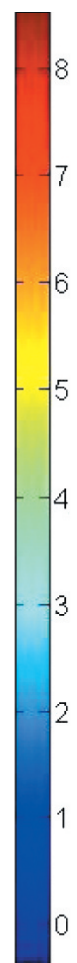

b)

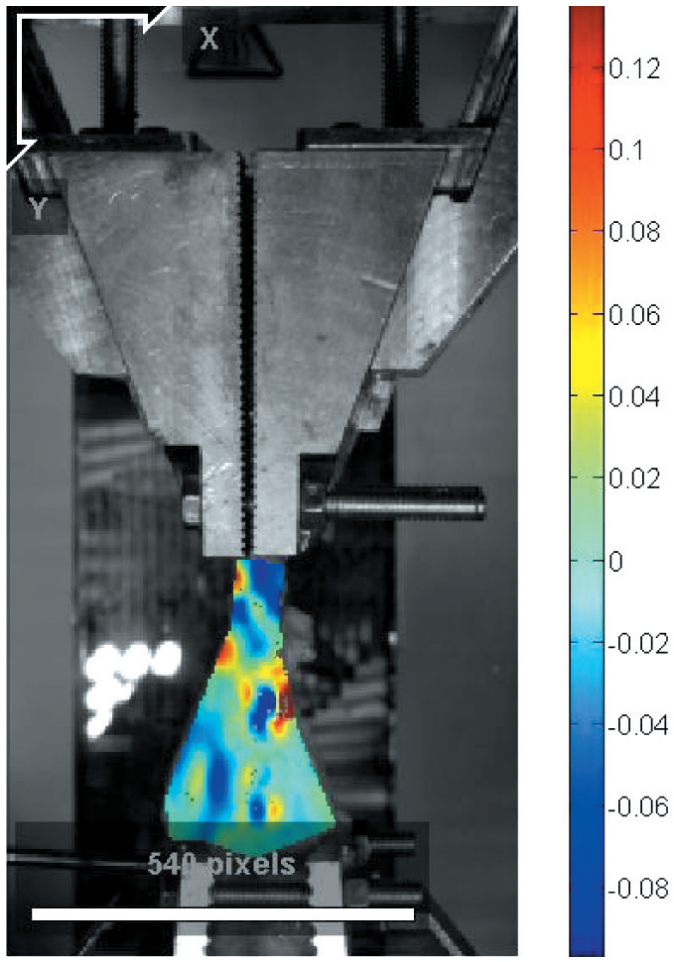

Fig. 4. Full-field data calculated using NCORR MATLAB software: a) displacement field $v$ component;

b) strain field $-\varepsilon_{y y}$ component

\section{RESULTS OF THE EXPERIMENT}

The tensile strain as a function of time was calculated based on the distance between pairs of points. Two pairs of points were considered in the investigation: $(2,3)$ and $(3,5)$. The $\varepsilon_{y y}$ strain component computed using the four analyzed software tools is presented in Figure 5 (strain computed using points 2 and 3 ) and Figure 6 (points 3 and 5). The root mean square (RMS) error of computation is summarized in Table 1. The DIC_3 results obtained using MotionProX are used as a reference.

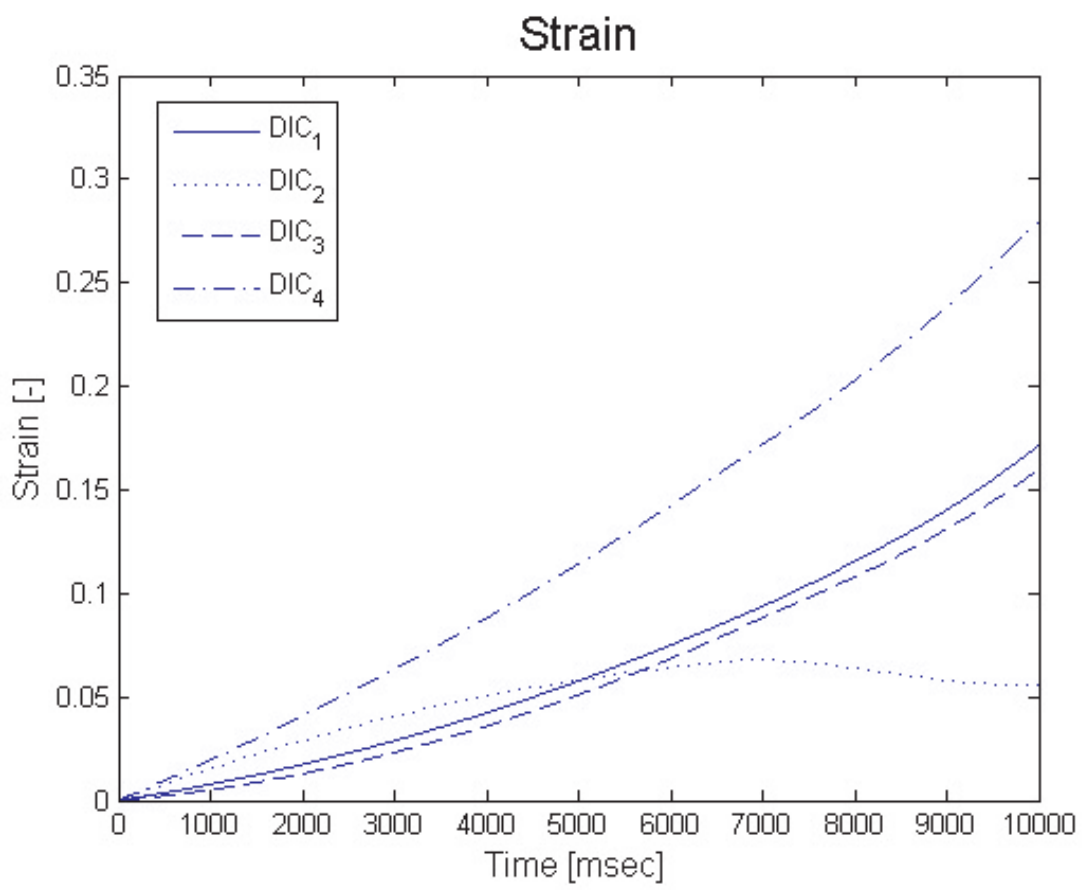

Fig. 5. Tensile strain $\left(\varepsilon_{y y}\right)$ computed based on displacement of points 2 and 3 


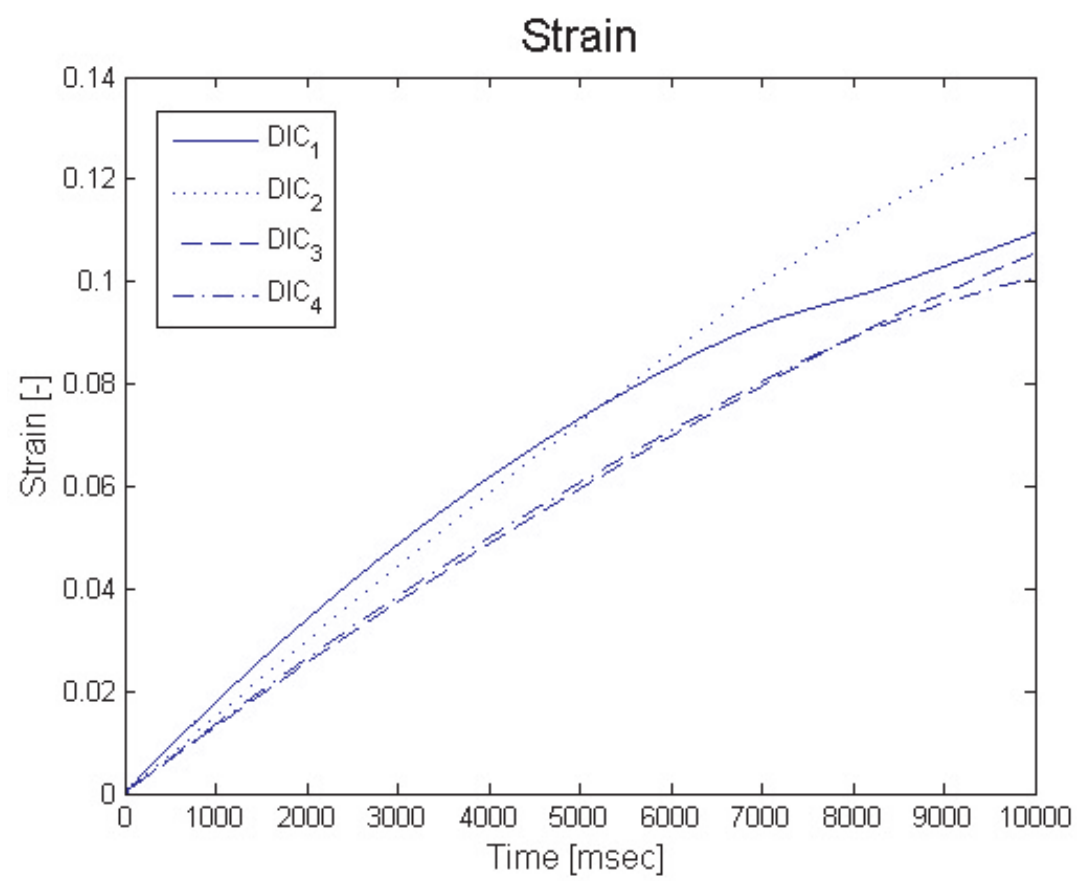

Fig. 6. Tensile strain $\left(\varepsilon_{y y}\right)$ computed based on displacement of points 3 and 5

Table 1

RMS error of DIC algorithms applied in the study

\begin{tabular}{|c|c|c|}
\hline Software & RMS (Points 2 and 3) & RMS (Points 3 and 5) \\
\hline DIC_1 & 0.0301 & 0.0068 \\
\hline DIC_2 & 0.0048 & 0.0074 \\
\hline DIC_4 & 0.0472 & 0.0070 \\
\hline
\end{tabular}

The error obtained using DIC_2 software was the smallest for two cases of the measured tensile strain. This was predictable, because the method uses gradient-based subpixel computation (which improves the accuracy of the measuremrnt). However, methods DIC_1 and DIC_4 each gave an error that was one order of magnitude larger than the one obtained by means of the DIC_2 algorithm. This can be understood by the fact that both of these methods use the rigid translational model of correlation implemented in MATLAB (in the case of DIC_1) or TEMA software (in the case of DIC_4). Therefore, the method is sensitive to the size of a chosen image patch as well as quality of the random speckle pattern. It cannot provide a proper mechanism for the correction of image patch affine or higher order deformation.

\section{CONCLUSIONS}

In the field of experimental mechanism applied for the examination of soft biological materials, non-contact measurement methods have become the most-important laboratory tool. The vision-based techniques are exceptionally useful because of their advantages. For example, one can show the digital image correlation-based method. They don't need any devices to be mounted on the samples and, therefore don't change the mechanical characteristics of the examined tissue. They are easy to use and require only simple preparation of a specimen by spray-painting a random texture pattern on its surface. Another important characteristic is the possibility of obtaining a full field of displacements and providing local strains instead of approximate mean values measured by contact devices (for example, extensometers). The laboratory tests performed on a sample of a human Achilles tendon revealed that all software that implements DIC (commercial as well as OpenSource) could be used for the computation of strain fields in tensile-testing scenarios. However, the rigid non-deformable correlation algorithm without sub-pixel improvement in accuracy may result in data that is characterized by larger error. It may also perform in an unpredictable manner. 


\section{Acknowledgments}

Reported research was realized within confines of project No.: UMO-2014/13/B/ST7/00690 co-financing by the National Science Center of Poland.

The project has Bioethics Commission agreement No. KBET/269/B/2011.

\section{References}

Arampatzis A., Peper A., Bierbaum S., Albracht K., 2010, Plasticity of human Achilles tendon mechanical and morphological properties in response to cyclic strain. Journal of Biomechanics 43, 3073-3079.

Bagheri Z.S., El Sawi I., Bougherara H., Zdero R., 2015, Biomechanical fatigue analysis of an advanced new carbon fiber/flax/epoxy plate for bone fracture repair using conventional fatigue tests and thermography. Journal of the Mechanical Behavior of Biomedical Materials 35, 27-38.

Bayliss A.J., Weatherholt A.M., Crandall T.T., Farmer D.L., McConnell J.C., Crossley K.M., Warden S.J., 2016, Achilles tendon material properties are greater in the jump leg of jumping athletes. Journal of Musculoskelet and Neuronal Interactions 16(2), 105-112.

Cyganik Ł., Binkowski M., Kokot G., Rusin T., Popik P., Bolechała F., Nowak R., Wróbel Z., John A., 2014, Prediction of Young's modulus of trabeculae in microscale using macro-scale's relationships between bone density and mechanical properties. Journal of the Mechanical Behavior of Biomedical Materials 36, 120-134.

Gillard F., Boardman R., Mavrogordato M., Hollis D., Sinclair I., Pierrona F., Browne M., 2014, The application of digital volume correlation (DVC) to study the microstructural behaviour of trabecular bone during compression. Journal of the Mechanical Behavior of Biomedical Materials 29, 480-499.

Helfenstein-Didier C., Andrade R.J., Brum J., Hug F., Tanter M., Nordez A., Gennisson J.L., 2016, In vivo quantification of the shear modulus of the human Achilles tendon during passive loading using shear wave dispersion analysis. Physics in Medicine and Biology 61, 2485-2496.
Koh I., López A., Helgason B., Ferguson S.J., 2014, The compressive modulus and strength of saturated calcium sulphate dihydrate cements: implications for testing standards. Journal of the Mechanical Behavior of Biomedical Materials 34, 187-198.

Latifi N., Miri A.K., Mongeau L., 2014, Determination of the elastic properties of rabbit vocal fold tissue using uniaxial tensile testing and a tailored finite element model. Journal of the Mechanical Behavior of Biomedical Materials 39, 366-374.

Ma S.P., Jin G.C., 2003, New correlation coefficients designed for digital speckle correlation method (DSCM). Proceedings of SPIE - The International Society for Optical Engineering 5058, $25-33$.

Obst S.J., Newsham-West R., Barrett R.S., 2016, Changes in Achilles tendon mechanical properties following eccentric heel drop exercise are specific to the free tendon. Scandinavian Journal of Medicine and Science in Sports 26, 421-431.

Pan B., Xie H., Xu B., Dai F., 2006, Performance of sub-pixel registration algorithms in digital image correlation. Measurement Science and Technology 17, 1615-1621.

Rashid B., Destrade M., Gilchrist M.D., 2014, Mechanical characterization of brain tissue in tension at dynamic strain rates. Journal of the Mechanical Behavior of Biomedical Materials, Special Issue on Forensic Biomechanics, 33, 43-54.

Sahoo S., DeLozier K.R., Dumm R.A., Rosen M.J., Derwin K.A., 2014, Fiber-reinforced dermis graft for ventral hernia repair. Journal of the Mechanical Behavior of Biomedical Materials 34, 20-29.

Sutton M.A., Cheng M.Q., Peters W.H., Chao Y.J. and McNeill S.R., 1986, Application of an optimized digital correlation method to planar deformation analysis. Image and Vision Computing 4(3), 143-151.

Sutton M.A., Turner J.L., Bruck H.A. and Chae T.A., 1991, Full-field representation of discretely sampled surface deformation for displacement and strain analysis. Experimental Mechanics 31(2), 168-177.

Takaza M., Moerman K.M., Simms C.K., 2013, Passive skeletal muscle response to impact loading: experimental testing and inverse modeling. Journal of the Mechanical Behavior of Biomedical Materials 27, 214-225. 